\title{
IMMEDIATE IMPLANT PLACEMENT IN FRESH EXTRACTION SOCKETS USING THE OPEN HEALING TECHNIQUE AND TISSUE LEVELIMPLANTS
}

\author{
Alecsandru lonescu ${ }^{1,2 a}$, Aliona Dodi'b ${ }^{10}$, Vasileios Panagopoulos ${ }^{10}$, Mihnea loan Nicolescu ${ }^{3,4 d^{*}}$, Augustin Mihai ${ }^{2 e}$, \\ Gabriela Tănase $^{2 f}$
}

\author{
${ }^{a}$ DDS, PhD student \\ ${ }^{\mathrm{b}} \mathrm{DDS}$ \\ 'DDS, MD, OMFS, PhD \\ ${ }^{\mathrm{d} D D S}, \mathrm{MD}$, OMFS, MSc, PhD, Lecturer \\ e DDS, PhD, Professor \\ 'DDS, PhD, Lecturer
}

'Aesthetics One Dental Center, Bucharest, Romania

${ }^{2}$ Implantology Division, Faculty of Dental Medicine, Carol Davila University of Medicine and Pharmacy, Bucharest, Romania

${ }^{3}$ Histology Division, Faculty of Dental Medicine, Carol Davila University of Medicine and Pharmacy, Bucharest, Romania

${ }^{4}$ Radiobiology Division, Victor Babes National Institute of Pathology, Bucharest, Romania

DOI: https://doi.org/10.25241/stomaeduj.2019.6(1).art.5

Introduction: Correctly managed, immediate implant placement into fresh extraction socket is a favorable treatment option in order to reduce the overall treatment time and to increase the patient's comfort and satisfaction.

Methodology: Atraumatic extractions $(\mathrm{N}=42)$ with socket preservation were performed in $n=40$ patients ( 0.74 sex ratio) followed by immediate placement of tissue level implants. Post extraction sockets were filled with either platelet-rich growth factors (PRGF) clots, or deproteinized bovine bone granules, or both; then covered by collagen resorbable membrane or cyanoacrylate and left exposed during healing. The pre-loading need for additional augmentation was assessed clinically and radiologically, using CBCT scans at $t=6$ months. The success and survival rate were evaluated by control CBCT scans at a 4 year follow-up.

Results: This analysis showed that "open healing" technique allowed uneventful healing and sufficient bone formation in combination with immediate placement of soft tissue level implants, a survival rate of $100 \%$ and a success rate of $95.2 \%$ at a $4 \mathrm{yr}$ follow-up. There were no significant differences regarding crestal bone level stability around the implants with the different augmentation materials.

Conclusion: Immediate placement of tissue level implants in fresh post extraction sockets using "open healing" approach can be favorable from both a clinical and radiological point of view considering the results at 4 years. In addition, soft-tissue problems associated with extensive flap mobilization and tension may be avoided and the 3D architecture of hard and soft tissues surrounding the implant may be maintained due to the tissue level implants design in accordance with the biological width when restored.

Keywords: Immediate implant placement; open healing; flapless; biological width.

OPEN ACCESS This is
an Open Access article under
the CC BY-NC 4.0 license.
Peer-Reviewed
Article
Citation: Ionescu A, Dodi A,
Panagopoulos V, Nicolescu Ml,
Mihai A, Tănase G. Immediate
implant placement in fresh
extraction sockets using the open
healing technique and tissue
level implants. Stoma Edu J.
2019;6(1):36-41.
Received: February 21, 2019
Revised: March 22, 2019
Accepted: March 26, 2019
Published: March 27, 2019
*Corresponding author:
Dr. Mihnea loan Nicolescu
Histology Division, "Carol Davila"
University of Medicine and
Pharmacy Bucharest, 8, Eroilor
Sanitari Blvd, District 5
R0-050474 Bucharest, Romania
Tel/Fax: +40722767260, e-mail:
mihnea.nicolescu@umfcd.ro
Copyright: $\odot 2019$ the
Editorial Council for the
Stomatology Edu Journal.

\section{Introduction}

Nowadays the first choice treatment option after extraction of failing teeth is represented either by immediate implant placement or by a socket preservation procedure [1,2]. Correctly managed, immediate implant placement into fresh extraction socket is a favorable treatment option in order to reduce the overall treatment time and to increase the patient's comfort and satisfaction [3]. Oral implantology has been intensively researched in basic as well as in clinical grounds [4]. In order to improve and accelerate healing of both hard and soft tissues after immediate implant placement, substitutes including growth factors and biomaterials have been traditionally employed and membranes were introduced to separate tissues [5]. It has been previously reported [6] that immediate implantation will not prevent resorption of the alveolar ridge. A recent systematic review analyzed the three-dimensional changes in bone tissue after immediate installation of a single implant in a fresh extraction socket, reaching a clear conclusion that bone remodeling occurs after tooth extraction even with immediate implant insertion [7]. One other recent systematic review described the effects of implants with different connections on the crestal bone level in relation with the surgical procedure after at least 12 months of functional loading. The conclusion was that platform-switched implants showed greater crestal bone preservation than non-platform-switched implants. There was no significant difference in the crestal bone loss with one- versus two-stage placement or the use of immediate versus delayed loading. Although there were statistically significant differences favoring immediate implant placement, as well as 
favorable outcomes for crestal bone level changes, the small differences may not be clinically relevant because of high heterogeneity among studies [8].

However, the use of immediate implantation techniques without raising a muco-periosteal flap, combined with a bone graft in the gap left between the implant and the post extraction socket walls, led to osseointegration accompanied by high stability of bone and the resulted soft tissue [7-9]. On the other hand, the use of tissue level implants is beneficial for the surrounding soft and hard tissues, especially when inserted with a flapless approach. Furthermore, the "open healing" technique used as an alternative ridge augmentation procedure, maintains a high stability of the crestal bone level as well as the architecture of the soft tissue after the healing period, with a good outcome even when resorptions of the buccal bone were present prior to extraction [10]. According to the literature, a classification system for management of molar extraction sockets is based upon the morphology of the septal bone and its influence on the implant's primary stability. Implants may be placed predictably into molar sockets when initial stability can be obtained within the septal bone, either entirely (Type A socket) or partially (Type B socket), or by engaging the walls at the periphery of the socket (Type $C$ socket). Otherwise, a delayed protocol should be utilized [11]. When it comes to monoradicular sites, especially in the esthetic zone, a simplified socket classification and repair technique was described: Type 1 - labial bone plate and associated soft tissues are completely intact; Type 2 - soft tissue is present, but a dehiscence osseous defect exists that is indicative of the partial or complete absence of the labial bone plate; Type 3 - midfacial recession defect is present, representing the loss of the labial bone plate and soft tissues [12]. A further classification of Type 2 socket defects where the soft tissue is present but a dehiscence osseous defect was later used to quantify the absence of the labial bone plate: Type $2 \mathrm{~A}$ - absence of the coronal one-third of labial bone plate of the extraction socket 5 to $6 \mathrm{~mm}$ from the free gingival margin; Type $2 \mathrm{~B}$ - absence of the middle to coronal two-thirds of the labial bone plate of the extraction socket approximately 7 to $9 \mathrm{~mm}$ from the free gingival margin; Type $2 \mathrm{C}$ - absence of the apical one-third of the labial bone plate of the extraction socket $10 \mathrm{~mm}$ or more from the free gingival margin [13].

This study shows the rationale behind immediate placement of a tissue level implant in the fresh extraction socket in conjunction with the "open healing" technique, showing not only the advantages of tooth extraction with minimal damage to the surrounding anatomic structures, but also how to maintain the implant surrounding hard and soft tissues threedimensional architecture, following the guidelines previously reported in the literature [14].

The aim of this retrospective analysis is to validate the protocol of immediate implant placement into fresh extraction sockets using open-healing approach and non-submerged (tissue-level) implants and to evaluate
I Table 1. Surgical site position.

A.

\begin{tabular}{lll}
\hline & Bone site & Number of Sites \\
\hline & Maxilla & $23(54.8 \%)$ \\
& Mandible & $19(45.2 \%)$ \\
\hline B. & & \\
\hline & Site region & Number of Sites \\
\hline & Anterior & $22(52.4 \%)$ \\
& Lateral & $20(47.6 \%)$ \\
\hline
\end{tabular}

the outcome of the surrounding bone at 12 and 24 month after loading.

\section{Materials and Methods}

This retrospective study evaluated patients treated between 2014-2018 in a private dental practice. The study protocol is in accordance with the Helsinki Declaration of 1975, revised in 2000 and was approved by the Ethics Committee. Every person involved in the study signed an informed consent. Patients with hopeless teeth with indication for extraction and implant therapy were recommended for the study. If primary stability could not be achieved or if the buccal bone plate was missing, such as there were no conditions to stabilize the implant in the healing phase, a delayed protocol was followed. The sites with indication for two stage approach were excluded from this study. There were 40 patients (sex ratio 0.74 ), with 42 surgical sites that met the conditions for immediate implant placement. After the teeth were extracted atraumatically, the extraction sockets were cleaned, and all granulation tissue was removed carefully.

We included surgical sites from the anterior and lateral regions of both maxilla and mandible (location frequency is detailed in Table $1-A, B)$. Both smokers (23.8\%) and non-smokers (76.2\%) were included in the study. Surgical interventions were performed according to our standard procedures. Tooth extraction was performed atraumatically, the roots where separated and extracted one by one in order to preserve the surrounding walls and interradicular septum. Of all the surgical sites, there were 2 sites that had two surrounding walls, 3 sites with three surrounding walls, the rest of the alveoli having all 4 surrounding walls. A tissue level implant was inserted into the neoalveolus created in the post extraction socket according to the initial 3D planning. Tissue level implants with similar Titanium alloy composition were used in all cases, 40 sites received standard $4.8 \mathrm{~mm}$ diameter platform conical implants (TRI Octa, TRI Dental Implants AG, Hünenberg, Switzerland) and 2 sites received wide neck $6.5 \mathrm{~mm}$ diameter platform cylindrical implants TissueLevel StandardPlus WN (Straumann AG, Basel, Switzerland).

Both implant types had a $1.8 \mathrm{~mm}$ high polished collar. The implants were placed having the polished collar at the same level with the cement-enamel junction (CEJ) level of adjacent teeth, with respect to the biological 
Table 2.Grafting material.

\begin{tabular}{ll}
\hline Grafting Material & Number of Sites \\
\hline Bio-Oss & $31(73.8 \%)$ \\
Copios & $7(16.7 \%)$ \\
Bio-Oss + PRGF & $3(7.1 \%)$ \\
No grafting material & $1(2.4 \%)$ \\
\hline
\end{tabular}

Table 3. Membrane type.

\begin{tabular}{ll}
\hline Membrane type & Number of Sites \\
\hline Histoacryl & $19(45.2 \%)$ \\
Bio-Gide & $18(42.9)$ \\
PRGF & $3(7.1 \%)$ \\
No membrane & $2(4.8 \%)$ \\
\hline
\end{tabular}

width protocol. The implant was installed in the septum in 4 sites, in other 3 sites the neoalveolus were created along the socket walls and in 35 sites new alveolae were created in another axis than the roots axis. In 2 of the sites in the molar region of the maxilla, internal lifting of the sinus membrane was performed in the same stage with implant insertion in the septum. No flap or deperiostation were performed in any of the 42 sites. The gaps of the alveolae where fulfilled either with deproteinized bovine bone granules (DBBO), with plasma rich in growth factors (PRGF) clots (Endoret - PRGF ${ }^{\circledR}$, BTI Biotechnology Institute, VitoriaGasteiz, Spain) mixed with DBBO or PRGF clots alone. The gaps were covered with a resorbable collagen membrane (RCM) or with a PRGF fibrine membrane. The membranes were stabilized with a PTFE continuous suture (Coreflon ${ }^{\circledR}$, Implacore Sp. z o.o. Poznań, Poland) that was applied to the free gingival margins. In caset the gap between the implant neck and the gingival margin was less than $4 \mathrm{~mm}$, a layer of cyanoacrylate was applied instead of the membrane and no suture was applied. There was one single site that neither received a graft material nor a membrane.

We used the following biomaterials: DBBO: Bio-Oss ${ }^{\circledR}$ (Geistlich Pharma, Wolhusen, Switzerland), Copios ${ }^{\circledR}$ (Zimmer Biomet Dental, Palm Beach Gardens, FL-USA) and RCM: Bio-Gide ${ }^{\circledast}$ (Geistlich Pharma, Wolhusen, Switzerland), Socket Repair Membrane ${ }^{\circledast}$ (Zimmer Biomet Dental, Palm Beach Gardens, FL-USA), Histoacryl ${ }^{\circledR}$ (B. Braun Medical, Melsungen, Germany) (Tables 2 and 3 ).

The patients received a specific scheme for control and follow up appointments. Clinical observations were made at 24 h, 48 h, 7 days and 14 days. The suture was removed after 21 days. Antibiotics were prescribed for prophylactic reason. Indications for cleaning and special care of the clinical sites were given. Painkillers and nonsteroidal anti-inflammatories were recommended just when needed. The suture removal took place after three weeks. In order to allow maturation of the bone and soft tissue, the sites were allowed to heal for at least six months before loading. We have chosen this aspect of the protocol based on previously success rate reported in the literature [15]. The case where no grafting material or membrane were used was planned to be loaded after three months, but the patient postponed the appointment until after six months due to personal reasons.

The CBCT scans were performed with the same investigation unit Cranex 3D (Soredex, Helsinki, Finland/ KaVo Dental Gmbh, Biberach, Germany) and analyzed with the OnDemand 3D software (CyberMed, Yuseonggu, Daejeon, Korea).

\section{Results}

During the observation period, a total of 41 patients with 43 surgical areas were treated with immediate implant placement in the post extraction site using the open-healing technique. One patient did not show up for prosthetic treatment, so we excluded him from the study. Therefore, the analysis included 42 surgical areas in 40 patients ( $42.5 \%$ male and $57.5 \%$ female). The nean patient age was $50.2 \pm 16.0$ years (aged $28-81$ years).

The clinical outcome was observed, checking parameters such as inflammation, swelling, pain and soft tissue secondary healing. The patients were scheduled at the specified time frame, 6 months before loading, for the CBCT scan in order to analyze the bone volume, crestal bone loss and the possibility of scheduling the implant loading procedures. All implants were loaded, using fixed single unit or multiunit cemented restorations, respecting the biological width protocol [16]. CBCT control scans were performed at 24 and 48 months follow-up. Success and survival rates were analyzed using the Buser criteria: (1) Absence of persistent subjective complaints, such as pain, foreign body sensation, and/or dysesthesia; (2) Absence of periimplant infection with suppuration; (3) Absence of mobility; (4) Absence of continuous radiolucency around the implant [17]. From the 42 sites, only 2 (two) cases needed additional surgery after clinical and CBCT observation at 6 months. Both sites were in the premolar area, one in the maxilla and one in the mandible, underwent the same procedure, using the exact same biomaterials (BioOss and BioGide). Both patients were suffering from the same systemic disease, Hepatitis, Type $C$ Virus. There was no relevant correlation with other factors. Of these 2 cases, one required additional bone augmentation procedure and the second one just a soft tissue remodeling procedure, yielding a survival rate of $100 \%$ and a success rate of $95.2 \%$ at the control time of 6 months after initial surgery. The CBCT scans showed a stable bone dimensions at 24 and 48 months followup intervals with a bone preservation of $98.9 \pm 0.7 \%$ and $98.1 \pm 0.9 \%$ compared with initial measurements. The results were analyzed and interpreted by the same clinician, in order to eliminate deviations. The bone parameters measured on CBCT scans showed stable results for all three bone levels mean values (buccal and oral bone plate height, and crest width - Table 4).

To sum up, the atraumatic extraction (Fig. 1) was followed by the tissue level implant insertion in the septum (Fig. 2). The "Open healing" technique is shown at one day, two days and three weeks in Fig. 3. Followups at one and three years (Fig. 4), as well as 4 years 
I Table 4.CBCT bone level measured parameters.

\begin{tabular}{llcccc}
\hline & & Mean & Std. Deviation & Minimum & Maximum \\
\hline \multirow{2}{*}{ Initial } & BP-height & 13.55 & 2.90 & 4.08 & 17.71 \\
& OP-height & 14.34 & 2.90 & 3.03 & 20.70 \\
\hline \multirow{2}{*}{ After loading } & BP-height & 13.73 & 1.74 & 10.70 & 17.17 \\
& OP-height & 14.26 & 1.87 & 8.97 & 18.99 \\
\hline \multirow{2}{*}{ loar after } & BP-height & 13.61 & 1.78 & 10.68 & 17.03 \\
\hline \multirow{2}{*}{$\begin{array}{l}\text { loading } \\
\text { loading }\end{array}$} & OP-height & 14.07 & 1.82 & 8.94 & 18.87 \\
\hline
\end{tabular}

$\mathrm{BP}=$ buccal bone plate, $\mathrm{OP}=$ oral bone plate. All measurements in $\mathrm{mm}$.

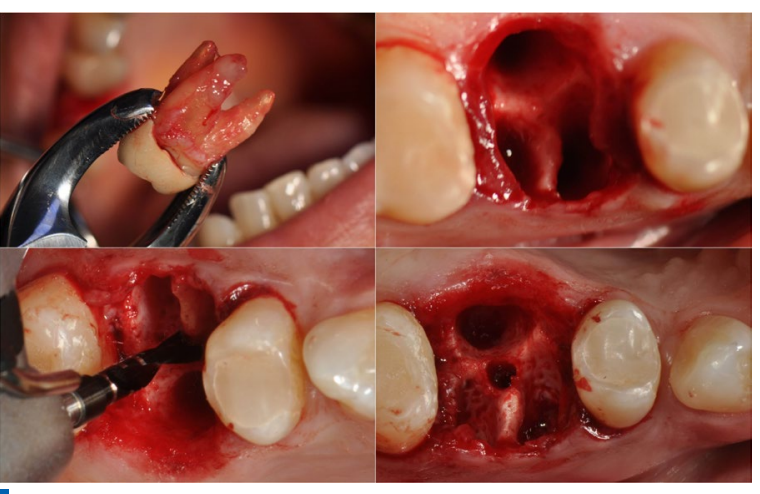

I Figure 1. Atraumatic extraction (a,b). Neoalveolus preparation in the $\operatorname{septum}(c, d)$.

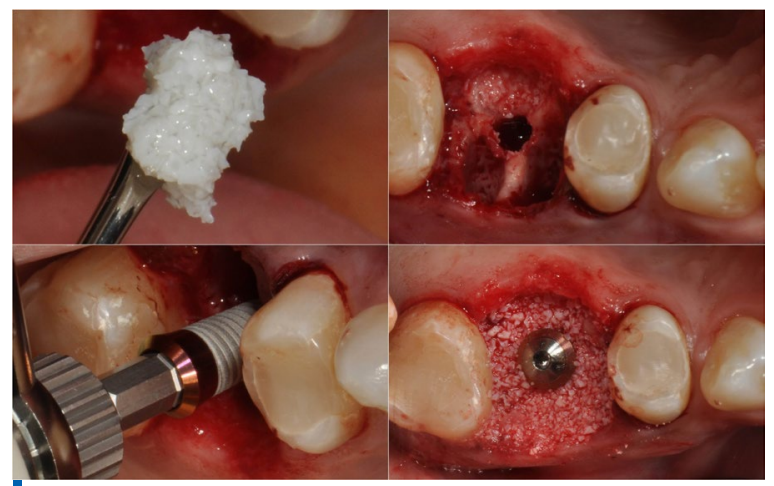

I Figure 2. Bovine bone granules filling the alveolae (a,b). Tissue level implant inserted in the septum $(c, d)$.

(Fig. 5) shape the picture of one of the cases that were successfully addressed using the protocol described in this study.

In our study, all implants obtained a good primary stability. The treatment was judged to be successful if implant loading was possible with no additional augmentation needed and implants were in place at the follow-up intervals, thus a success rate of $95.2 \%$. The survival rate after criteria described by Buser et al in 1997 was $100 \%$ [18].

\section{Discussions}

In order to facilitate the implant therapy, ridge resorption caused by tooth extraction should be limited or even eliminated. The evaluation of bone quality during treatment planning is mandatory

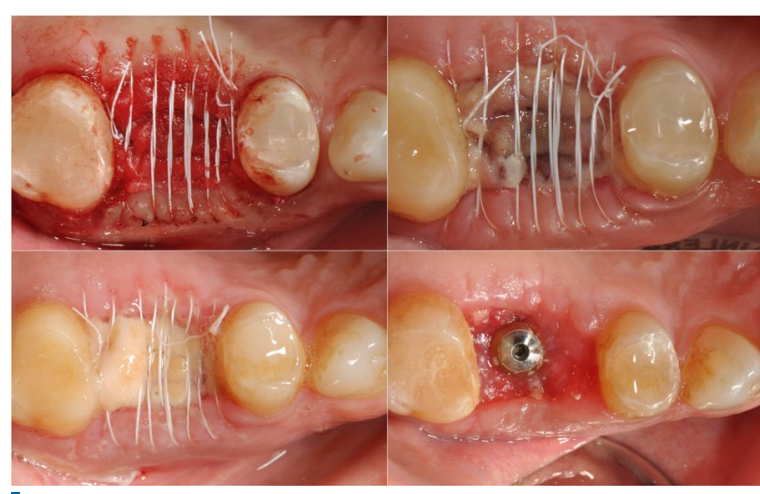

I Figure 3. Open healing. Resorbable collagen membrane stabilized by PTFE continuous suture (a). Healing at 24h (b), 48h (c) and 3 weeks (d).

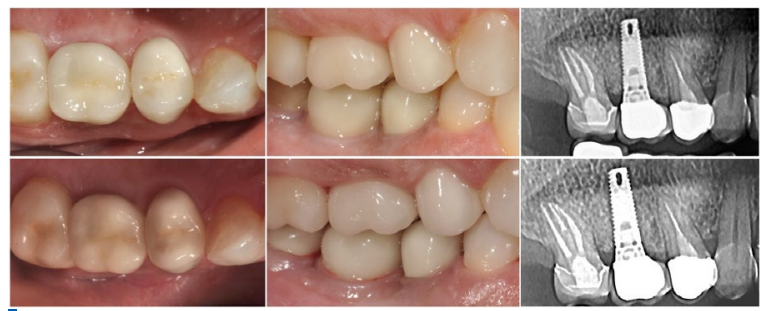

Figure 4. Follow-up at 12 months (clinical - $\mathrm{a}, \mathrm{b}$ and radiological $-\mathrm{c}$ ) and at 36 months (clinical - d,e and radiological $-f$ ).

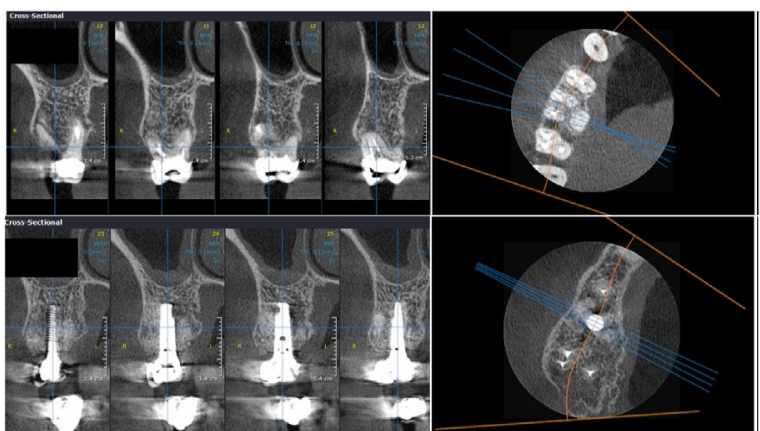

Figure 5. CBCT scan before surgery (up) and at 4 years follow up (down), showing implant position in the septum.

especially when immediate loading is intended. Positive results regarding the possible implant stability can lead to immediate implant insertion as the first choice clinical procedure instead of a delayed two-stage approach. Such a delayed-approach treatment sequence encompasses several steps over an extended period of time and appointments, not only for the practitioner, but also for the patient. Barone et al. [19] showed that regenerative techniques 
(GBR) were able to limit resorption of the alveolar crest after implant placement in a fresh extraction socket. On the contrary, Hsu et al. [20] demonstrated in an experimental study that the placement of implants and deproteinized bovine bone granules into fresh extraction sockets generates significant buccal bone loss as well as low osseointegration. Other clinical studies [21-23] used GBR techniques to fill the gap between bone and implant.

Our study showed that placing a bone graft into the residual gap around a post-extraction socket is helpful for limiting the amount of facial-palatal contour change from the FGM to more apical reference points. In a retrospective cohort study conducted by Tarnow et al. the conclusion stated was that all post-extraction implant placement without flap elevation demonstrated some negative contour change (facial collapse) relative to the adjacent contralateral control tooth. However, the change was minimal compared to previous studies where full periosteal flaps were elevated for ridge augmentation after teeth extraction. According to these authors, the key elements in preserving ridge contour are protection, containment and maintenance of the bone graft during the healing phase of treatment, which can extend from 4 to 6 months. A contoured healing abutment or provisional restoration were used to close the gap and keep the graft in place [24]. Alternatively, our concept is based on the tissue level emergency profile design that can seal the gap similarly to the contoured healing abutment. The advantage of our technique compared to the above-mentioned ones is that having the tissue level in place after the osseointegration period, there will be no trauma of the peri-implant tissues generated by the dismounting of the healing abutment or provisional crown and mounting the final prosthesis. When the tissue level implant's neck was not wide enough to close the space left, cyanoacrylate tissue glue was used to protect the bone graft [14]. In gaps that are larger than $4 \mathrm{~mm}$, a collagen resorbable membrane was placed over and stabilised with a continuous PTFE suture, according to the described "open healing" protocol. Although various studies have shown controversial results regarding the effect of secondary wound dehiscence occurring during healing when using suitable membrane materials, the protocol allows uneventful healing and sufficient bone formation. Also, soft-tissue problems associated with extensive flap mobilisation and tension may thus be avoided.

\section{Conclusion}

This retrospective study indicates that immediate implant placement into fresh extraction sockets using tissue level implants, suitable grafting materials and membranes with the "open healing" protocol allows uneventful healing, predictable aesthetic results and lower surgical trauma compared with conventional methods using flap techniques. Furthermore, the softtissue problems associated with flap mobilization and consecutive tension due to the wound closure are avoided. The clinical significance of the combination of the "open healing" technique, with immediate implant placement of a tissue level implant into a fresh extraction socket with partial or complete loss of the buccal bone plate has significant benefits for both the clinician and the patient: treatment procedures are reduced to fewer appointments, the overall time of the treatment is reduced and the tridimensional architecture of the soft and hard tissues is maintained, including the possibility of regenerating the buccal bone plate when missing. Further scientific studies need to be conducted to reinforce our clinical results.

\section{Author contributions}

All the authors participated in establishing the concept and protocol. Al, AD, VP performed the surgical procedures. MIN, AM, GT participated in data gathering, analysis and interpretation. All the authors participated in critically revising the manuscript.

\section{References}

1. Hämmerle $\mathrm{CH}$, Chen ST, Wilson JrTG. Consensus statements and recommended clinical procedures regarding the placement of implants in extraction sockets. Int JOral Maxillofac Implants. 2004; 19(Suppl):26-28.

[PubMed] Google Scholar Scopus

2. Hämmerle CH, Araújo MG, Simion M, Osteology Consensus Group 2011. Evidence-based knowledge on the biology and treatment of extraction sockets. Clin Oral Implants Res. 2012;23(Suppl 5):80-82.

[CrossRef] [PubMed] Google Scholar Scopus

3. Jung $\mathrm{RE}$, loannidis A, Hämmerle $\mathrm{CH}$, Thoma DS. Alveolar ridge preservation in the esthetic zone. Periodontology 2000. 2018;77(1):165-175.

[CrossRef] [PubMed] Google Scholar

4. Tomlin EM, Nelson SJ, Rossmann JA. Ridge preservation for implant therapy: a review of the literature. Open Dent J. 2014;16(8):66-76.

[CrossRef] [PubMed] Google Scholar Scopus

5. Sehgal M, Puri, L, Yadav S et al. Immediate Dental Implants Enriched with L-PRF in the Esthetic Zone. Case Rep Dent. 2018; 9867402.

[Free PMC Article] [CrossRef] [PubMed] Google Scholar Scopus

6. Botticelli D, Berglundh T, Lindhe J. Hard-tissue alterations following immediate implant placement in extraction sites. J Clin Periodontol. 2004;31(10):820-828

[CrossRef] [PubMed] Google Scholar Scopus

7. Denardi RJ, da Silva RD, Thomé G et al. Bone response after immediate placement of implants in the anterior maxilla: a systematic review. Oral Maxillofac Surg. 2019 Feb. [Full text links] [PubMed] Google Scholar Scopus

8. Mehta H, Shah S. Management of Buccal Gap and Resorption of Buccal Plate in Immediate Implant Placement: A Clinical Case Report. JInt Oral Health. 2015;7(Suppl 1):72-75. [Full text links] [PubMed] Google Scholar

9. Gotta SL, Reynolds MA, Saito H, Tarnow DP. Flapless post extraction socket implant placement, part 2: the effects of bone grafting and provisional restoration on peri-implant soft tissue height and thickness-a retrospective study. Int $J$ Periodontics Restorative Dent. 2015;35(6):803-809. Google Scholar

10. Ionescu A, Panagopoulos V, Taffet G. Open healing protocol as alternative ridge augmentation procedure in implant patients. Clinical Oral Implants Research. 2015;26:441.

11. Smith RB, Tarnow DP. Classification of molar extraction sites for immediate dental implant placement. Int JOral Maxillofac Implants. 2013 May-Jun;28(3):911-916.

[CrossRef] [PubMed] Google Scholar Scopus

12. Elian N, Cho S, Froum S et al. A simplified socket classification and repair technique. Pract Proced Aesthet Dent. 2007 Mar;19(2):99-104. [PubMed] Google Scholar Scopus

13. Chu SJ, Sarnachiaro GO, Hochman MN, Tarnow DP. Subclassification and Clinical Management of Extraction Sockets with Labial Dentoalveolar Dehiscence Defects. Compend Contin Educ Dent. 2015 Jul-Aug;36(7):516, 518-20, 522 passim. [PubMed] Google Scholar Scopus 
14. Taffet G. Open healing: a retrospective analysis. J Oral Science Rehabilitation. 2016; 2(4):16-25.

15. Botticelli D, Renzi A, Lindhe J, Berglundh T. Implants in fresh extraction sockets: a prospective 5-year follow-up clinical study. Clin Oral Implants Res. 2008;19(12):1226-1232. [CrossRef] [PubMed] Google Scholar Scopus

16. Taffet G. Implantate in der ästhetischen Zone Im Konflikt oder in Harmonie mit der ",biologischen Breite"? DGZI Impl J 2009;(7):48-53. Google Scholar

17. Buser $D$, Ingimarsson $S$, Dula K et al. Long-term stability of osseointegrated implants in augmented bone: a 5-year prospective study in partially edentulous patients. Int $J$ Periodontics Restorative Dent. 2002 Apr;22(2):109-117. [PubMed] Google Scholar Scopus

18. Buser D, Mericske-Stern R, Bernard JP et al. Long-term evaluation of non-submerged ITI implants. Part 1: 8-year life table analysis of a prospective multi-center study with 2359 implants. Clin Oral Implants Res. 1997;8(3):161-172.

[CrossRef] [PubMed] Google Scholar Scopus

19. Barone A, Ricci M, Calvo-Guirado JL et al. Bone remodelling after regenerative procedures around implants placed in fresh extraction sockets: an experimental study in Beagle dogs. Clin Oral Implants Res. 2011;22(10):1131-1137.

[CrossRef] [PubMed] Google Scholar Scopus

20. Hsu KM, Choi BH, Ko CY et al. Ridge alterations following immediate implant placement and the treatment of bone defects with Bio-Oss in an animal model. Clin Implant Dent Relat Res. 2012;14(5):690-695.

[CrossRef] [PubMed] Google Scholar Scopus

21. Cafiero C, Annibali S, Gherlone E et al. Immediate transmucosal implant placement in molar extraction sites: a 12-month prospective multicenter cohort study. Clin Oral Implants Res. 2008;19(5):476-482

[CrossRef] [PubMed] Google Scholar Scopus

22. Matarasso S, Salvi GE, lorio Siciliano V et al. Dimensional ridge alterations following immediate implant placement in molar extraction sites: a six-month prospective cohort study with surgical re-entry. Clin Oral Implants Res. 2009;20(10):1092-1098. [CrossRef] [PubMed] Google Scholar Scopus

23. Siciliano VI, Salvi GE, Matarasso S et al. Soft tissues healing at immediate transmucosal implants placed into molar extraction sites with buccal self-contained dehiscences. A 12-month controlled clinical trial. Clin Oral Implants Res. 2009;20(5):482-488. [CrossRef] [PubMed] Google Scholar Scopus

24. Tarnow DP, Chu SJ, Salama MA et al. Flapless postextraction socket implant placement in the esthetic zone: part 1. The effect of bone grafting and/or provisional restoration on facial-palatal ridge dimensional change-a retrospective cohort study. Int $J$ Periodontics Restorative Dent. 2014;34(3):323-331. [CrossRef] [PubMed] Google Scholar

\section{Alecsandru IONESCU \\ DDS, PhD Student \\ Aesthetics One Dental Center \\ Bucharest, Romania}

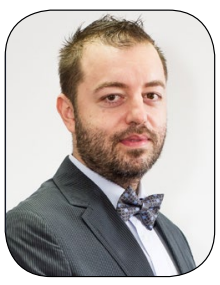

Dr. Alecsandru lonescu graduated from the Faculty of Dentistry, "Carol Davila” University of Medicine and Pharmacy Bucharest, Romania (2001). He is a member of the board of the Society for Esthetic Dentistry in Romania (SSER). He is also the co-founder of Quintessence International Romania and a founding member of the Romanian Society for Digital Dentistry. He is an active member of IADFE, ESCD, EAO and ICOI. Dr. lonescu's main lecturing topics focus on minimally invasive approaches in oral surgery and implantology. $\mathrm{He}$ is an international speaker, author of different articles and a co-author of the "Comprehensive Esthetic Dentistry", the first volume by Romanian authors published by Quintessence International in 2015, translated into Chinese in 2017. He works in Bucharest in his private clinic and training center "Aesthetics One".

\section{Drestions}

\section{In which situation is immediate implant placement possible?}

口a. When primary stability can be obtained;

ab. In type A socket;

c. In all socket types;

$\square d$. After all granulation tissue is removed and the alveolae are cleaned.

\section{Buser criteria for survival and success are:}

$\square$ a. Absence of any postoperative edema;

ab. Absence of mobility;

c. Absence of continuous radiolucency around the implant;

$\square$ d. Absence of periimplant infection with suppuration.

\section{The following is true about immediate implantation:}

$\square$ a. It reduces the overall treatment plan;

b. It stops the postextractional bone loss;

ac. It can be done in conjunction with the open healing technique;

$\square d$. The polished collar must be placed at the same level as the cement-enamel junction.

\section{To facilitate implant placement:}

口a. Tooth extraction must be atraumatic;

ab. Postextractional bone loss must be minimized;

ac. A mucoperiosteal flap should be raised;

$\square$ d. Additional augmentation should be performed. 